Research Paper

\title{
Cell Therapy with Human MSCs Isolated from the Umbilical Cord Wharton Jelly Associated to a PVA Membrane in the Treatment of Chronic Skin Wounds
}

\author{
Jorge Ribeiro ${ }^{1,2,10}$, Tiago Pereira1,2, Irina Amorim ${ }^{3,4}$, Ana Rita Caseiro, ${ }^{1,2,5}$, Maria A Lopes ${ }^{6}$, Joana Lima ${ }^{7}$,
} Andrea Gartner2, José Domingos Santos 6 , Paulo J Bártolo5 ${ }^{5}$, Jorge Manuel Rodrigues²,8,9, Ana Colette Mauricio ${ }^{1,2}$, Ana Lúcia Luís ${ }^{1,2,10}$

1. Departmento de Clínicas Veterinárias, Instituto de Ciências Biomédicas de Abel Salazar (ICBAS), Universidade do Porto (UP), Rua de Jorge Viterbo Ferreira, $\mathrm{n}^{\circ}$ 228, 4050-313 Porto, Portugal.

2. Centro de Estudos de Ciência Animal (CECA), Instituto de Ciências e Tecnologias Agrárias e Agro-Alimentares (ICETA), Rua D. Manuel II, Apartado 55142, 4051-401, Porto, Portugal.

3. Departmento de Patologia e de Imunologia Molecular, Instituto de Ciências Biomédicas de Abel Salazar (ICBAS), Universidade do Porto (UP), Rua de Jorge Viterbo Ferreira, $n^{\circ} 228,4050-313$ Porto, Portugal.

4. Instituto Português de Patologia e Imunologia Molecular da Universidade do Porto (IPATIMUP), Rua Dr. Roberto Frias s/n, 4200-465 Porto, Portugal.

5. CDRsp - Centro para o Desenvolvimento Rápido e Sustentado de Produto, Instituto Politécnico de Leiria, Centro Empresarial da Marinha Grande, Rua de Portugal - Zona Industrial, 2430-028, Marinha Grande, Portugal.

6. CEMUC, Departamento de Engenharia Metalúrgica e Materiais, Faculdade de Engenharia, Universidade do Porto, Rua Dr. Roberto Frias, 4200-465 Porto, Portugal.

7. LEPABE - Laboratory for Process Engineering, Environment, Biotechnology and Energy, Faculdade de Engenharia da Universidade do Porto (FEUP), Rua Dr. Roberto Frias, 4200-465, Porto, Portugal

8. Hospital de S. João, Universidade do Porto (UP), Porto, Portugal.

9. Departmento de Dentistria, Universidade Fernando Pessoa (UFP), Praça 9 de Abril, 349, 4249-004 Porto, Portugal.

10. UPVET, Instituto de Ciências Biomédicas de Abel Salazar (ICBAS), Universidade do Porto (UP), Rua de Jorge Viterbo Ferreira, $\mathrm{n}^{\circ} 228,4050-313$ Porto, Portugal. Porto.

$\triangle$ Corresponding author: Prof. Ana Colette Maurício, Departamento de Clínicas Veterinárias, Instituto de Ciências Biomédicas Abel Salazar (ICBAS), Rua de Jorge Viterbo Ferreira, $\mathrm{n}^{\circ}$ 228, 4050-313 Porto, Portugal. Mobile: +351919071286; Phone: +351220428000; Email: ana.colette@hotmail.com, acmauricio@icbas.up.pt

(C) Ivyspring International Publisher. This is an open-access article distributed under the terms of the Creative Commons License (http://creativecommons.org/ licenses/by-nc-nd/3.0/). Reproduction is permitted for personal, noncommercial use, provided that the article is in whole, unmodified, and properly cited.

Received: 2014.03.17; Accepted: 2014.06.10; Published: 2014.07.II

\begin{abstract}
The healing process of the skin is a dynamic procedure mediated through a complex feedback of growth factors secreted by a variety of cells types. Despite the most recent advances in wound healing management and surgical procedures, these techniques still fail up to $50 \%$, so cellular therapies involving mesenchymal stem cells (MSCs) are nowadays a promising treatment of skin ulcers which are a cause of high morbidity. The MSCs modulate the inflammatory local response and induce cell replacing, by a paracrine mode of action, being an important cell therapy for the impaired wound healing. The local application of human MSCs (hMSCs) isolated from the umbilical cord Wharton's jelly together with a poly(vinyl alcohol) hydrogel (PVA) membrane, was tested to promote wound healing in two dogs that were referred for clinical examination at UPVET Hospital, showing non-healing large skin lesions by the standard treatments. The wounds were infiltrated with 1000 cells/ $\mu \mathrm{l}$ hMSCs in a total volume of $100 \mu \mathrm{l}$ per $\mathrm{cm}^{2}$ of lesion area. A PVA membrane was applied to completely cover the wound to prevent its dehydration. Both animals after the treatment demonstrated a significant progress in skin regeneration with decreased extent of ulcerated areas confirmed by histological analysis. The use of Wharton's jelly MSCs associated with a PVA membrane showed promising clinical results for future application in the treatment of chronic wounds in companion animals and humans.
\end{abstract}

Key words: Chronic wounds, mesenchymal stem cells, Wharton's jelly, PVA hydrogel, histology. 


\section{Introduction}

Proper cutaneous wound repair requires a good coordination of inflammation, neovascularisation, extracellular matrix (ECM) formation and epithelialisation. When skin is severely damaged, the ability to repair itself is limited resulting in hypertrophic scars, so-called keloid scar, and consequent non-healing, or ulceration, or excessive scar contraction of the wound. Traditional therapies for treatment of chronic wound include surgical debridement, minimization of local bacterial multiplication; pressure off-loading, negative-pressure therapy, skin grafting and reconstructive tissue flaps. Despite the most recent advances in wound healing management and surgical procedures, these techniques still fail up to $50 \%$ [1]. The difficulty of the healing process of chronic wounds might be due to local ischemia, reperfusion injury, bacterial infection, or aging resulting in chronic inflammation [2]. Also in non-healing wounds the cell pool is intrinsically impaired and might demonstrate increased senescence and decreased response to growth factors $[3,4]$. MSCs present high plasticity, proliferative and differentiation capacity together with important immunosuppressive properties and low immunogenicity due to a decreased Human Leucocyte Antigen (HLA) class II expression [5-9], representing a promising cellular system to improve wound healing.

There are many studies involving mice and humans which have consistently demonstrated enhanced wound repair following treatment by infiltration or lesion local application, with bone marrow-derived MSCs [10, 11] or MSCs from other sources, like the umbilical cord blood (UCB) [12] and adipose tissue [13] Analysis of the mechanical properties of treated wounds revealed that administration of MSCs not only accelerated wound closure but also enhanced wound repair quality, resulting in repaired tissue with increase tensile strength. This effect is thought to be secondary to an increased in collagen composition within the repaired tissue [14].

MSCs isolated from the umbilical cord matrix (Wharton's jelly) have many advantages, such as, shorter population doubling time; can be easily cultured in plastic flasks, are well tolerated by the receptor immune system, so transplantation into non-immune-suppressed animals does not induce acute rejection, have anticancer properties [7] and most important are not tumorigenic $[15,16]$. For these reasons we believe that cellular therapy using MSCs from the Wharton's jelly in chronic wounds treatment is a promising field of investigation with great interest in Regenerative Medicine.

The MSCs delivery method is also very important and some authors used subcutaneous injection, systemic injection, intradermal injection and topical applications or combinations of these routes $[17,18]$. The clinical effectiveness of MSCs-based therapy is dependent on the number of cells delivered and survival, so it is important to optimize the delivery procedure. Falanga and collaborators utilized a fibrin spray system to topically administer autologous MSCs to non-healing lower extremity wounds in human subjects detecting considerable clinical improvements $[18,19]$. Hydrogels, as new generation synthetic biomaterials, are being developed at a fast speed to be used as three-dimensional extracellular microenvironment in order to simulate the regulatory characteristics of natural ECMs and ECM-bound growth factors, both for therapeutic applications and basic biology studies. Although modern synthetic biomaterials represent oversimplified mimics of natural ECMs lacking the essential natural temporal and spatial complexity, a growing symbiosis of engineered materials and cell biology, it may eventually result in synthetic materials that contain the necessary signalling to run through development processes in tissue- and organ-specific differentiation and morphogenesis [20].

This would be ideal for topical application of the MSCs demonstrating significant accelerated wound closure and improved quality of cutaneous regeneration with an increased number of hair follicles and sebaceous glands when compared to intradermal injection strategies [18].

On the other hand based on the nature of wounds and healing approaches, several materials have been developed for use in wound dressings and bandages [21]. The crucial requirements of an ideal wound dressing includes: pain control, easy replacement, transparency to facilitate the healing follow up, absorption and prevention of body fluid losses, existing barrier against bacteria, oxygen $\left(\mathrm{O}_{2}\right)$ permeability, easy handling, and drug dosage control. Polysaccharides based hydrogels are good materials for wound dressings since they can adhere to the wound side protecting it from external milieu. They are transparent, so the clinical observation of wound site and healing process can be easily monitored; they also can be tailored into various shapes and sizes, they are permeable to $\mathrm{O}_{2}$ and carbon dioxide $\left(\mathrm{CO}_{2}\right)$ but prevent the passage of microorganism [15].

The PVA is a water-soluble synthetic polymer and is prepared via the hydrolysis of poly(vinyl-acetate), in which the acetate groups are replaced by hydroxyls. In medical devices, PVA is being used as a biomaterial due to its biocompatibility, swelling properties, bio-adhesive characteristics, and for being non-toxic and non-carcinogenic $[6,22]$. PVA may mimic the regulatory characteristics of natural ECMs and ECM-bound growth factors, both in 
clinical applications and in basic biology studies [20].

The two patients referred to UPVET Hospital ICBAS, University of Porto, Portugal, were previously treated with standard treatment protocols with no clinical improvement; and in both animals it was not possible to perform free grafts or rotational flaps. So, it was decided to use human MSCs (hMSCs) from Wharton's jelly therapy associated to the application of a PVA membrane. The results are presented and discussed here.

\section{Materials and Methods}

\section{Poly(vynil-alcohol) hydrogel (PVA) membranes}

Membranes of PVA (Aldrich, Mowiol 10-98) with a thickness of about $1 \mathrm{~mm}$ were prepared using a casting technique. A $15 \%(\mathrm{w} / \mathrm{v})$ aqueous solution of PVA was used. The membranes were produced by a freezing/thawing process consisting in three cycles of freezer $\left(-30^{\circ} \mathrm{C}\right) /$ incubator $\left(25^{\circ} \mathrm{C}\right)$. The membranes were hydrated during $2 \mathrm{~h}$ before use.

\section{Cell Culture of human MSCs (hMSCs) from Wharton's jelly umbilical cord, viability and karyotype analysis}

Human MSC from Wharton's jelly UC (hMSCs) were purchased from PromoCell GmbH (C-12971, lot-number: 8082606.7). Cryopreservated cells were cultured and maintained in a humidified atmosphere with $5 \% \mathrm{CO}_{2}$ at $37^{\circ} \mathrm{C}$. Mesenchymal Stem Cell Medium (PromoCell, C-28010) was replaced every 48 hours. At $90 \%$ confluence, cells were harvested with $0.25 \%$ trypsin with EDTA (Gibco) and passed into a new flask for further expansion. hMSCs at a concentration of 2500 cell $/ \mathrm{ml}$ were cultured and after 24 hours cells exhibited 30-40\% confluence. Mesenchymal Stem Cell Medium (PromoCell, C-28010) was replaced every 48 hours. The phenotype, the cell morphology, adherence rate and viability of the hMSCs was assessed by PromoCell by rigid quality control tests. Each cell lot was characterized by flow cytometry analysis for a comprehensive panel of markers [23]. The hMSCs established PromoCell cell line exhibited a mesenchymal-like shape with a flat and polygonal morphology in culture. During expansion the cells became long spindle-shaped and colonized the whole culturing surface (Figure 1). At 90\% confluence, cells were harvested with $0.25 \%$ trypsin with EDTA (Gibco) and a suspension of 1000cells/ $\mu$ l was prepared in insulin syringes to facilitate the surgical procedure. The hMSCs infiltration was performed in a total volume of $100 \mu \mathrm{l}$ per $\mathrm{cm}^{2}$ of lesion area. Chromosome analysis on the hMSCs before in vivo application was carried out between passages 4 and 5, as previously described [23]. Chromosome analysis was performed by one scorer on 20 Giemsa-stained metaphases. Each cell was scored for chromosome number. Routine chromosome G-banding analysis was also carried out for determination of the karyotype. Intracellular free $\mathrm{Ca}^{2+}$ concentration $\left(\left[\mathrm{Ca}^{2+}\right]_{i}\right)$ was measured in Fura-2-loaded cells by using dual wavelength spectrofluorometry as previously described $[23,24]$. The measurements were performed on undifferentiated hMSCs cultured on PVA membrane discs after confluence was obtained, in order to correlate the hMSCs ability to expand and survival capacity in the presence of the biomaterial. The application of the hMSCs isolated from the umbilical cord Wharton's jelly in dogs is possible without inducing immunessupression, as previously referred.

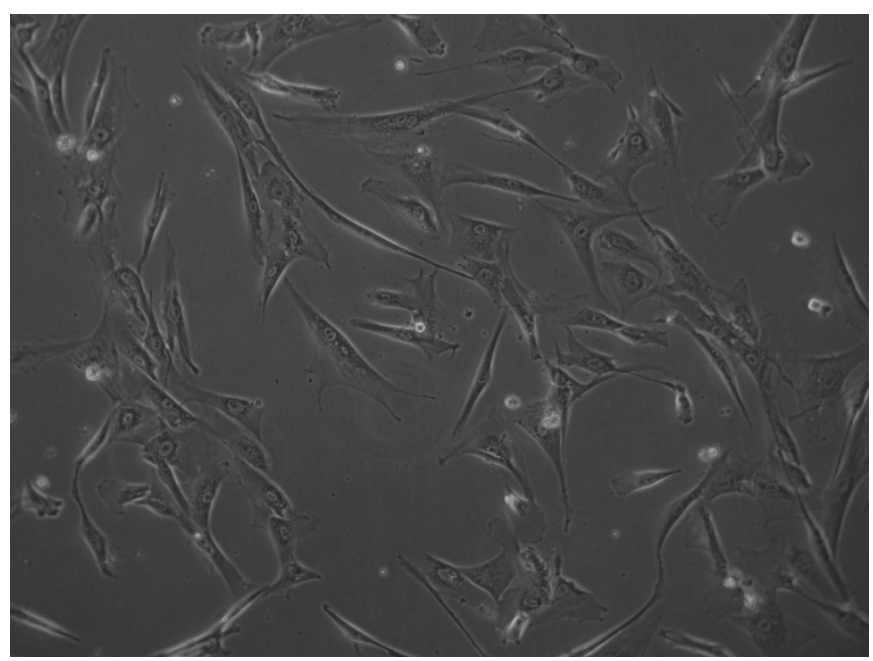

Figure I - Undifferentiated human mesenchymal stem cells (hMSCs), from human umbilical cord Wharton's jelly, exhibiting a star-like shape with a flat morphology (Magnification: 100x).

\section{Physical examination and surgical procedure}

The clinical cases concerning two dogs were referred for examination at UPVET Hospital - ICBAS, University of Porto, Portugal. In clinical case 1, a 2 years old, $32 \mathrm{~kg}$ neutered male mixed breed dog, presented a chemical burn injury with a 16-month history of clinical presentation and evolution and without any healing response to several and previous standard treatments. The lesion involved the left thoracic and abdominal wall and consisted of two main central and ulcerated areas, measuring $7.0 \times 2.0 \mathrm{~cm}$ and $3 \times 3 \mathrm{~cm}$ and surrounded by an exuberant fibrous scar (Figure 2A).

In the clinical case 2, a 5 years old, $34 \mathrm{~kg}$ spayed female mixed breed dog, presented a similar but smaller lesion, with a 24-month history of evolution and also refractory to the conventional treatments previously instituted. The ulcerated lesion was local- 
ized in the sacro-iliac region and measured $6 \times 5 \mathrm{~cm}$, presenting peripheral fibrosis (Figure 3A). The cause of the injury was unknown. After a complete physical examination, the only abnormal finding in both animals was the deep and extensive skin ulcerated lesions affecting the epidermal and dermal layers. By the time of the surgery (pre-treatment biopsy), both animals were submitted to a skin biopsy performed with a scalpel blade number 23 . Collected tissues were then fixed in $10 \%$ buffered formalin, paraffin-embedded, 3- $\mu \mathrm{m}$ thick cut and stained with haematoxylin and eosin (HE) for histological examination.
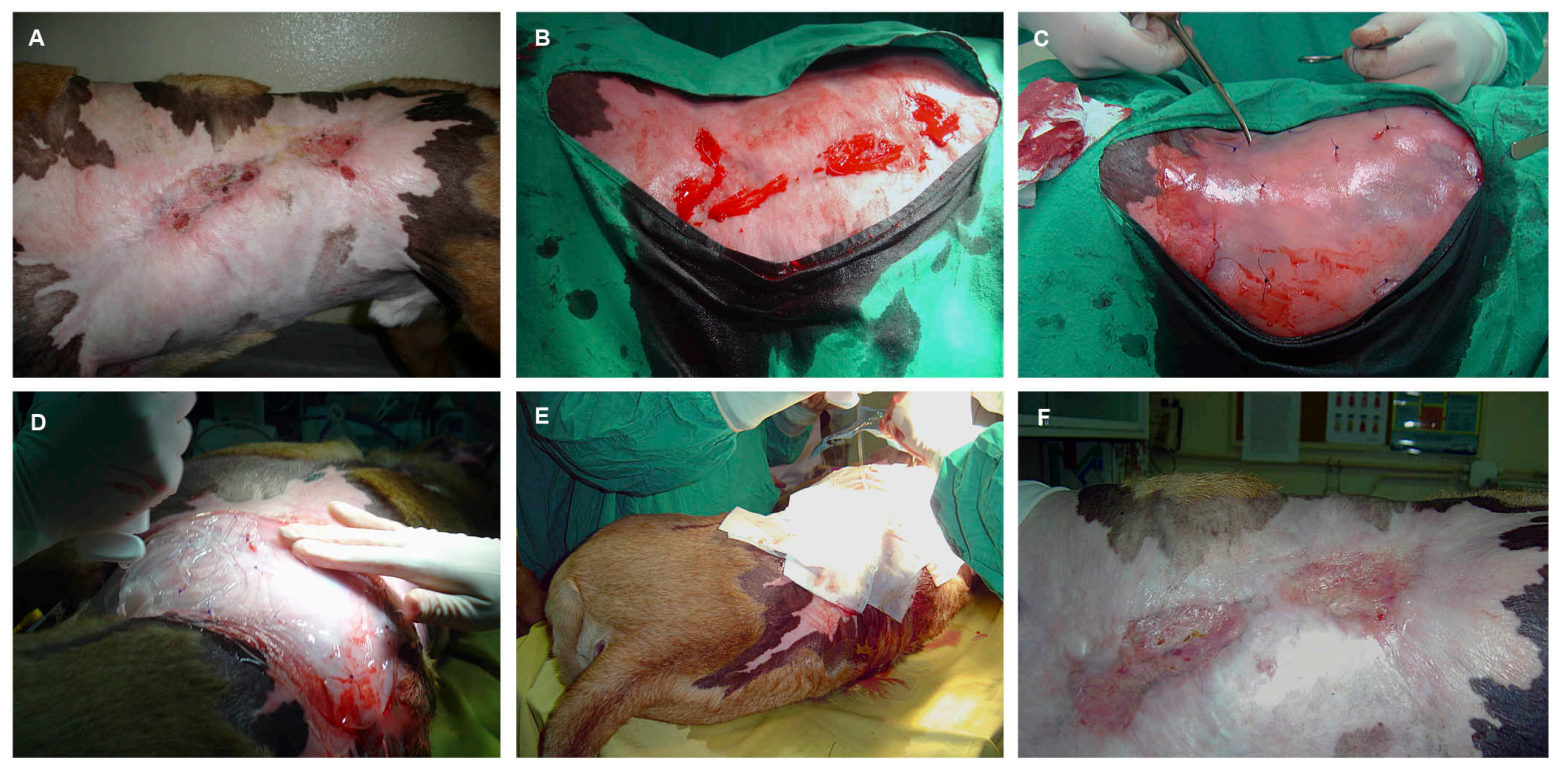

Figure 2 - In clinical case I, it can be observed an extensive chemical burn injury in the left thoracic wall with two central ulcerated areas presenting approximately $7 \mathrm{~cm} \times 2 \mathrm{~cm}$ and $3 \mathrm{~cm} \times 3 \mathrm{~cm}$ surrounded by an extensive fibrous scar (A). Surgical biopsy and wound debridement (B). PVA membrane application over the lesion area, after the hMSCs intradermal infiltration (C). Moisture retentive bandage over the PVA membrane to prevent lesion dissecation (D, E). Complete cicatrization 2 months after human hMSCs local application (F).
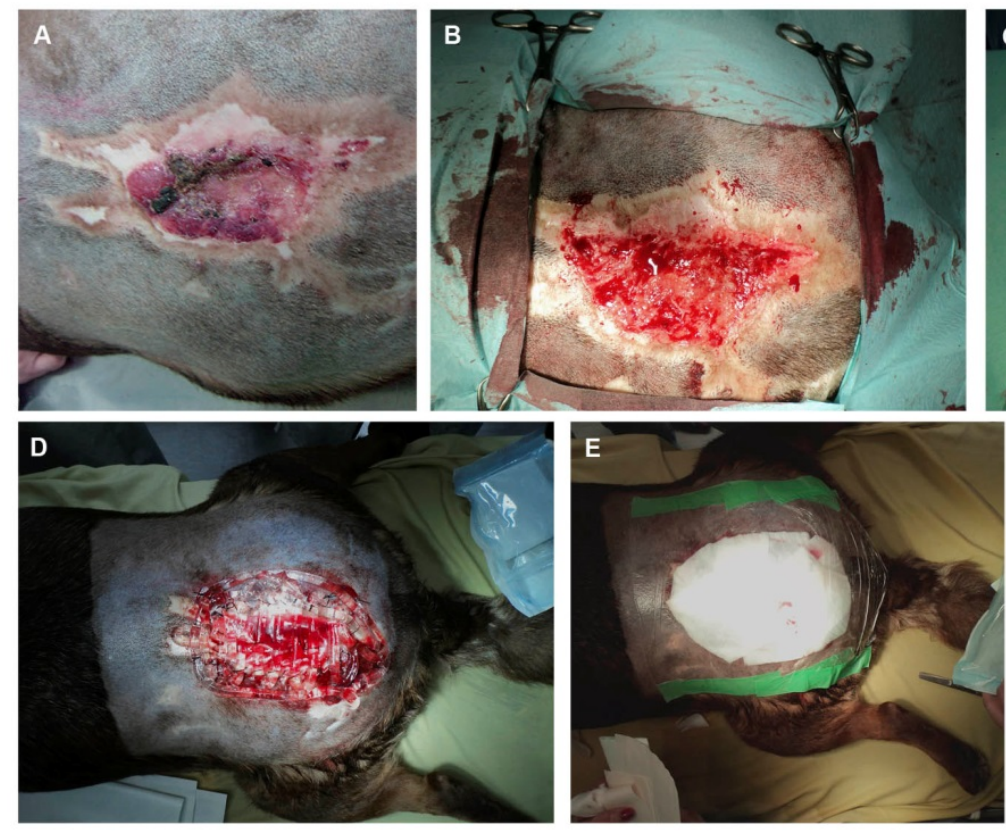

Figure 3 - In clinical case 2 the lesion was localized in the sacro-iliac region and measured approximately $6 \mathrm{~cm} \times 5 \mathrm{~cm}$, with a central ulcerated and necrotic area presenting peripheral fibrosis. The lesion was of unknown cause (A). Surgical biopsy and wound debridement (B). Intradermal hMSCs application (C). Moisture retentive bandage over the PVA membrane to prevent lesion dissecation (D, E). Complete cicatrization 2 months after human hMSCs local application (F). 
Both animals were previously subjected to standard clinical treatments for inducing healing by second intention, like healing ointments, hydrogel bandages and sugar bandages. In clinical case 1, an improvement occurred (in the area correspondent to the fibrosis area) until cicatrization process stopped without complete closure of the wound. The wound remained without any sign of improvement for about 16 months.

For the hMSCs application, both animals were pre-medicated with morphine $(0,5 \mathrm{mg} / \mathrm{kg})$ and diazepam $(0,2 \mathrm{mg} / \mathrm{kg})$, induced with propofol $(4 \mathrm{mg} / \mathrm{kg})$ and maintained with isoflorane $2 \%$. The affected area was surgically prepared. The edges of the wound were debrided (Figure 2B and Figure 3B) and the undifferentiated hMSCs from Wharton's jelly of human umbilical cord, previously isolated and expanded in vitro were locally infiltrated at a concentration of 1000 cells/ $\mu$ l in culture medium (Figure 1, Figure 3C). The hMSCs infiltration was performed in a total volume of $100 \mu \mathrm{l}$ per $\mathrm{cm}^{2}$ of lesion area. Methylprednisolone was intravenously administered (Solu-medrol 125®, Pfizer, $1 \mathrm{mg} / \mathrm{kg}$ ). Antibiotherapy was performed in both patients with Enrofloxacin $5 \mathrm{mg} / \mathrm{kg}$ once a day for 15 days. Finally, a sterile PVA membrane was applied to prevent desiccation of the wound (Figure $2 \mathrm{C}$ and Figure 3D), and a moisture-retentive dressing was applied over it and changed twice a day until day 3 after surgery (Figure 2D, Figure 2E, Figure 3E). Afterwards, the wound dressing was changed daily for the next 15 days. After this period, the PVA membranes were removed and non-adherent dressings were applied over the lesion area and daily changed during 10 more days. After complete cicatrization (2 months after the surgery) a second skin biopsy was performed to the clinical case 1 , in attempt to evaluate the progress of the lesion. Unfortunately the second skin biopsy was not performed in clinical case 2 , since the owners did not authorized it.

\section{Results}

\section{hMSCs cell culture, viability and karyotype analysis}

Undifferentiated hMSCs from umbilical cord Wharton's jelly exhibited a normal star-like shape with a flat morphology in culture (Figure 1). A total of 20 Giemsa-stained metaphases of these cells, were analysed for numerical aberrations. Sporadic, non-clonal aneuploidy was found in 1 cell (45 chromosomes). The other 19 metaphases had 46 chromosomes. The karyotype was determined in a completely analysed G-banding metaphase and no structural alterations were found. The karyotype analysis performed demonstrated once again, like in previous published experimental work [23], that this cell line has not neoplastic characteristics and is stable during the cell culture procedures in terms of number and structure of the somatic and sexual chromosomes. Results obtained from epifluorescence technique $\left[\mathrm{Ca}^{2+}\right]_{i}$ measurements with the undifferentiated hMSCs corresponded to cells that did not begin the apoptosis process. The undifferentiated hMSCs cultured on PVA membranes reached confluence and exhibited a normal star-like shape with a flat morphology in culture. According to these results, it is reasonable to conclude that PVA membranes are a viable substrate for undifferentiated human MSCs adhesion, and expansion (Figure 1).

\section{Clinical follow-up and Histological Examination}

There were no clinical complications in the post-operative period and after 2 months a complete epithelialisation was observed in both cases (Figure 2F and Figure $3 \mathrm{~F}$ ). The animals remained without any discomfort, pain or prurience throughout this period.

Prior to the hMSCs-based therapy with a PVA membrane procedure, in clinical case 1 , microscopically, the affected skin presented an extensive and irregular epidermal hyperplasia, with various orthokeratotic hyperkeratosis and parakeratosis foci. Several and multifocal areas of ulceration covered by serocellular crusts containing numerous clusters of bacteria, associated with large amount of inflammatory infiltrate, consisting predominantly of neutrophils and fewer lymphocytes were also observed. The dermis displays images of exuberant fibrosis and dermal-epidermal dissociation. It was not possible to identify skin appendages (Figure 4A and Figure 4B).

In clinical case 2 , focal epidermal ulceration was observed with the histological exam. The dermis was constituted in its almost entire length by dense connective tissue showing few nuclei and cells, with the presence of various hemorrhage and fibrinoid necrosis areas (Figure 5A and Figure 5B).

By the time of the second biopsy (2 months), in clinical case 1 , the epidermal showed moderate orthokeratotic hyperplasia and presence of multifocal serocellular crusts. Areas of dermal fibrosis and absence of skin appendages were still prominent features however, in the superficial dermis, an exuberant granulation tissue was noted, rich in active fibroblasts and dilated neo-vessels coated by tall columnar endothelium. Moderate amount of diffuse mononuclear cell infiltration (macrophages, plasma cells and lymphocytes) was also present (Figure 4C and Figure 4D). 

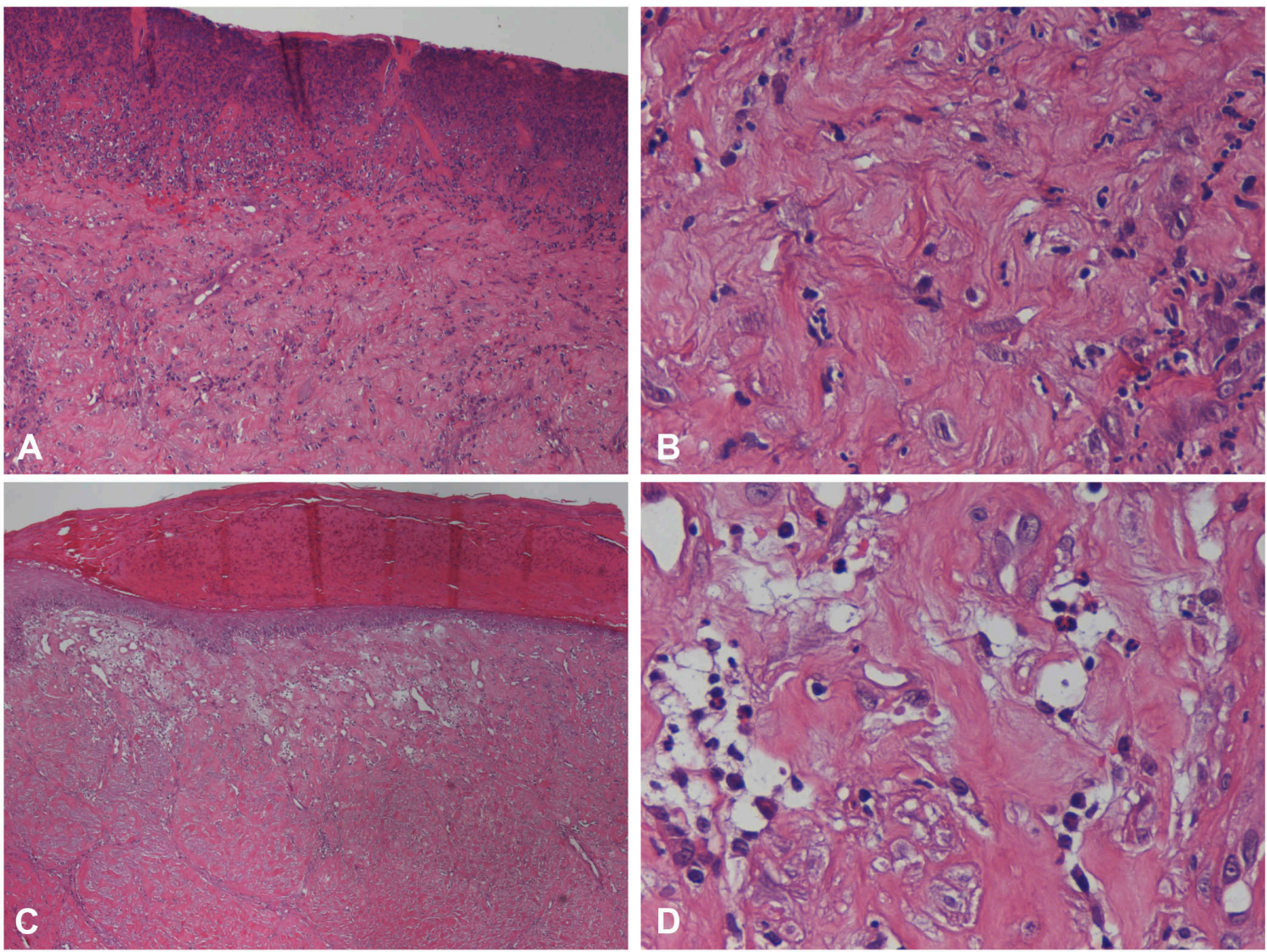

Figure 4 - Histopathological findings of clinical case I skin biopsy. Before the scaffold application (pre-treatment biopsy), the affected skin presented severe and multifocal areas of ulceration (A and B), associated with large amount of inflammatory infiltrate consisting predominantly of neutrophils. The dermis displays images of exuberant fibrosis. It was not possible to identify skin appendages. This could be observed using HE and a magnification of I00x (A) and 400x (B). At day 60 after the hMSCs application, the epidermal showed signs of re-epithelization presenting orthokeratotic hyperplasia and multifocal serocellular crusts, $\mathrm{HE}, 40 \mathrm{x}$ (C). In the underlying dermis an exuberant granulation tissue was noted, with several fibroblasts and dilated neovessels containing neutrophils, HE, 400x (D).
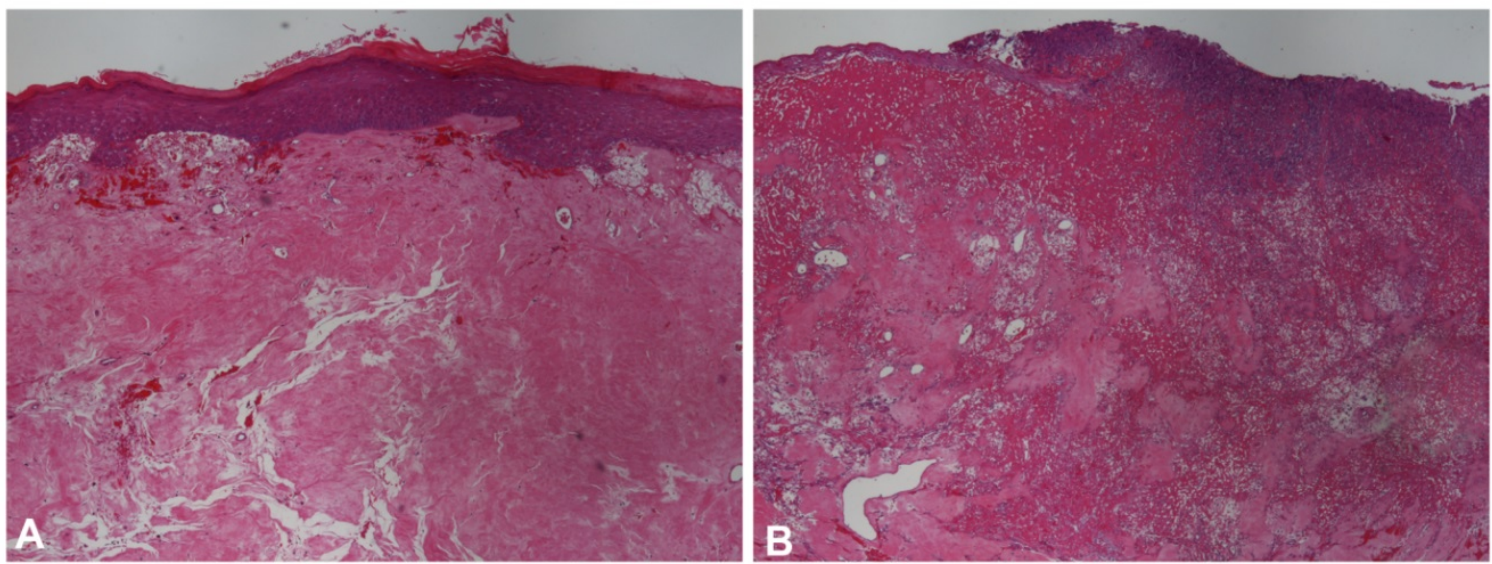

Figure 5 - Histopathological findings of clinical case 2 skin biopsy. Before the scaffold application (pre-treatment biopsy), the dermis was constituted in its almost entire length by dense connective tissue showing few nuclei and cells, HE and magnification of 40x (A). Ulceration, hemorrhage and fibrinoid necrosis areas were also observed in the mid- to superficial dermis, HE and magnification of $40 \times(B)$.

\section{Discussion}

Tissue engineering is a multidisciplinary research field that combines the ideologies of engineering and life sciences together to develop biological substitutes to restore, maintain or improve tissue function. Therefore there are emerging cellular therapies as an alternative for organ and tissue transplan- tation. MSCs have become one of the most interesting cells for tissue engineering since these cells present high plasticity, proliferative and differentiation capacity and immunosuppressive properties due to a decreased or even absence of HLA class II expression [25]. Currently the differentiation potential of MSCs in multi-lineage end-stage cells is already proven, and 
their potential for treatment of cardiovascular [26], neurological [27], musculoskeletal [28], and cutaneous [1] diseases is now well established. MSCs can be obtained from many different tissues, including bone marrow, adipose tissue, skeletal muscle, umbilical cord matrix and blood, placental tissue, amniotic fluid, synovial membranes, dental pulp, foetal blood, liver and lung [29-34]. These cells are important for the Regenerative Medicine field because they have anti-inflammatory and immunomodulate properties by cytokines and growth factors production [35, 36]. As a matter of fact, the therapeutic effects of MSCs are due to their ability to repair damage tissue, to their capacity of modulating surrounding environment, and of activating endogenous progenitor cells $[37,38]$. Also, several studies have demonstrated that MSCs, have a higher chromosomal stability and lower tendency to form tumours and teratomas, compared to other stem cells, for instance, embryonic stem cells (ESCs) [39-41].

The local application of hMSCs isolated from the umbilical cord Wharton's jelly together with a PVA membrane, was tested to promote wound healing in two dogs that were referred for clinical examination at UPVET Hospital, showing non-healing large skin lesions after standard treatments failure.

In these two clinical trials, the karyotype analysis of the hMSCs cell line derived from the Wharton's jelly locally applied, demonstrated that this cell line did not have neoplastic characteristics and was stable during the cell culture procedures in terms of number and structure of the somatic and sexual chromosomes. Also, the results obtained from $\left[\mathrm{Ca}^{2+}\right]_{\mathrm{i}}$ epifluorescence measurements performed with hMSCs cultured on PVA discs, confirmed that these cells that did not begin the apoptosis process and were viable cells. The undifferentiated hMSCs in vitro cultured on PVA membranes reached confluence and exhibited a normal star-like shape with a flat morphology in culture, which proved the citocompatibility of this biomaterial. According to these results, it is reasonable to conclude that PVA membranes are a viable substrate for undifferentiated hMSCs adhesion, and multiplication. The option to have chosen a physically, instead of the chemically, cross-linked PVA membranes aimed to avoid releasing of chemical compounds from a classic chemical cross-linking technique that could interfered with cell behaviour. As reported elsewhere [42], the freezing/thawing technique leads to anisotropic microstructure materials. The processing route chosen in this study produced PVA membranes with a structure, morphology and stability adequate to be used with cellular systems like the hMSCs from the umbilical cord Wharton's jelly.

The healing process is a complex and dynamic phenomenon which normally happens in a very orderly and efficient manner in order to restore the anatomical continuity and tissue function. The normal healing cascade begins with haemostasis and fibrin deposition which leads to an inflammatory cell cascade, characterized by neutrophils, macrophages and lymphocytes within the tissue. This is followed by attraction and proliferation of fibroblast and collagen deposition and finally remodelling by collagen cross-linking and scar maturation. If any part of this healing sequence is altered, pathologic responses can occur, leading to fibrosis and chronic ulcers [43]. In some pathological conditions the lesions stay trapped in a state of chronic inflammation characterized by abundant neutrophil infiltration, as described in clinical case 1 before the hMSCs and PVA application. The neutrophils release enzymes responsible for the destruction of the connective tissue matrix, for the inhibition of important healing factors and are associated with reactive oxygen species that cause cell damage. When tissues are injured, the fibroblasts synthesize collagen which is essential to repair the defect and restore the tissue anatomic structure and function [43]. However, if an excessive amount of collagen is deposited, the normal anatomical structure is lost, function is compromised and fibrosis occurs with reduced remodelling, similarly to that seen in clinical case 2 before the scaffold application. In both described clinical cases, the healing process would possible proceed if the inflammation was controlled and the wound bed was properly prepared.

Histological analysis over time of clinical case 1 indicated that hMSCs-treated wound showed more stable features in the epidermal layer compared with day 0 , suggesting a more mature epithelium. A noteworthy change in the nature of the inflammatory infiltrate was recorded: neutrophils were gradually replaced by mononuclear cells associated with granulation tissue formation, suggesting that the classical healing sequence was overtaken. It was also observed that, by the time of the second biopsy, the treated wound was involved by a denser capillary network when compared with the biopsy analysis performed prior to the scaffold application, suggesting that the treatment applied promoted angiogenesis in the dermis. These results suggest that in clinical case 1 , the hMSCs infiltrated in the wound accelerated epidermal and dermal renewal. Despite the absence of the second biopsy to confirm the histopathological evolution of the lesion, the clinical course of the case 2 is clearly remarkably since, as you can see in figure 3, panel $\mathrm{F}$, the rate of wound closure and re-epithelialization was accelerated, the quality and strength of the regenerated tissue was improved and the visual appearance of the lesion was minimize. All 
these evidences, taken together, suggest that the application of hMSCs could accelerate wound healing, promoting angiogenesis and providing the cells and cellular factors needed to create the optimal wound-healing microenvironment in canine chronic wounds.

Previous studies showed that MSCs exhibit a considerable and important number of trophic functions to enhance tissue regeneration (for review see the published work of Jackson et al., 2012 [44]), such as modulating the inflammatory response (by regulating the function of the leukocytes present in the lesion) and promoting angiogenesis. Once the MSCs enter the inflammatory environment due to chemotaxis, their immunomodulatory phenotype is activated by interferon- $\gamma(\mathrm{IFN} \gamma)$, tumour necrosis factor- $\alpha$ (TNFa) and interleukin-1 $\beta$ (IL-1 $\beta$ ) [45]. It is also well documented the ability of MSCs to regulate T-cell recruitment, proliferation and activity [45] and their capability of suppressing the proliferation of B cells [46] and natural killer cells [47], thereby improving the acute immune response to injury [48]. By attenuating the function of these cell types, the MSCs would likely reduce the pro-fibrotic responses that can occur coincident with prolonged inflammation during wound healing [49]. Moreover, some studies reported that engrafted MSCs in the wound improved angiogenesis by exerting a paracrine effect which increases levels of angiogenic factors such as angiopoietin- 1 and vascular endothelial growth factor (VEGF) [50].

In both clinical cases described, both patients were not good candidates to do rotational flaps or free grafts since the extension and location of the lesions did not allow obtaining healthy skin to transpose and the free grafts had very small chance to be successful since their irrigation would be very compromised by the skin architecture of the surrounding tissues. The results of our study reinforced the efficacy of therapy with hMSCs on enhancing wound healing in dogs by promoting epidermal and dermal regeneration and angiogenesis. However, further studies are needed in order to investigate if its administration may thus represent a novel therapeutic approach and to clinically explore further improvements in canine cutaneous wound therapy.

It was concluded that, in both clinical cases the association of hMSCs from Wharton's jelly of human umbilical cord and PVA membrane did not present any negative effect and even improved the wound healing, in two clinical cases where the standard treatments failed. This cellular therapy associated to a PVA membrane should be further investigated in order to be applied in the future in veterinary clinical practice as in human medicine.

\section{Acknowledgements}

The authors would like to thanks to the owners of Kika and Sunny. I Amorim (SFRH/BD/76237/ 2011) acknowledge FCT, the Portuguese Foundation for Science and Technology, for financial support. The Institute of Molecular Pathology and Immunology of the University of Porto (IPATIMUP) is an Associate Laboratory of the Portuguese Ministry of Science, Technology and Higher Education and is partially supported by FCT. This research was supported by QREN I\&DT Cluster in Development of Products for Regenerative Medicine and Cell Therapies - Projects Biomat \& Cell QREN 2008/1372, co-financed by the European Community FEDER fund through ON2 - O Novo Norte - North Portugal Regional Operational Program 2007-2013, by project "Hybrid Nanostructured Hydrogels: Bone regeneration using Multifunctional injectable Hydrogels - Rebone" - ENMED/ 0002/2010 from FCT, Ministério da Educação e da Ciência and Program Project Euronanomed, Ref: EraNet - EuroNanoMed JTC2010, and by the program COMPETE - Programa Operacional Factores de Competitividade, Project Pest-OE/AGR/UI0211/ 2011.

\section{Competing Interests}

The authors have declared that no competing interest exists.

\section{References}

1. Chen JS, Wong VW, Gurtner GC. Therapeutic potential of bone marrow-derived mesenchymal stem cells for cutaneous wound healing. Front Immunol. 2012; 3: 10 .

2. Mustoe TA, O'Shaughnessy K, Kloeters O. Chronic wound pathogenesis and current treatment strategies: a unifying hypothesis. Plast Reconstr Surg. 2006; 117: 35S-41S.

3. Hasan A, Murata H, Falabella A, Ochoa S, Zhou L, Badiavas E, et al. Dermal fibroblasts from venous ulcers are unresponsive to the action of transforming growth factor-beta 1. J Dermatol Sci. 1997; 16: 59-66.

4. Vande Berg JS, Rudolph R, Hollan C, Haywood-Reid PL. Fibroblast senescence in pressure ulcers. Wound Repair Regen. 1998; 6: 38-49.

5. Gotherstrom C, Ringden $O$, Westgren M, Tammik C, Le Blanc K. Immunomodulatory effects of human foetal liver-derived mesenchymal stem cells. Bone marrow transplantation. 2003; 32: 265-72. doi:10.1038/sj.bmt.1704111.

6. Secco M, Zucconi E, Vieira NM, Fogaca LL, Cerqueira A, Carvalho MD, et al. Mesenchymal stem cells from umbilical cord: do not discard the cord! Neuromuscular disorders : NMD. 2008; 18: 17-8. doi:10.1016/j.nmd.2007.11.003.

7. Kim DW. Cotransplantation of third-party mesenchymal stromal cells can alleviate single-donor predominance and increase engraftment from double cord transplantation. Blood. 2004; 103: 1941-8. doi:10.1182/blood-2003-05-1601.

8. McFarlin K, Gao X, Liu YB, Dulchavsky DS, Kwon D, Arbab AS, et al. Bone marrow-derived mesenchymal stromal cells accelerate wound healing in the rat. Wound Repair and Regeneration. 2006; 14: 471-8.

9. Nasef A, Mathieu N, Chapel A, Frick J, François S, Mazurier C, et al. Immunosuppressive effects of mesenchymal stem cells: involvement of HLA-G. Transplantation. 2007; 84: 231-7.

10. François S, Mouiseddine M, Mathieu N, Semont A, Monti P, Dudoignon N, et al. Human mesenchymal stem cells favour healing of the cutaneous radiation syndrome in a xenogenic transplant model. Annals of hematology. 2007; 86: $1-8$

11. Lataillade J, Doucet C, Bey E, Carsin H, Huet C, Clairand I, et al. New approach to radiation burn treatment by dosimetry-guided surgery combined with autologous mesenchymal stem cell therapy. 2007. 
12. Malgieri A, Kantzari E, Patrizi MP, Gambardella S. Bone marrow and umbilical cord blood human mesenchymal stem cells: state of the art. International journal of clinical and experimental medicine. 2010; 3: 248.

13. Fu X, Fang L, Li H, Li X, Cheng B, Sheng Z. Adipose tissue extract enhances skin wound healing. Wound repair and regeneration. 2007; 15: 540-8.

14. McFarlin K, Gao X, Liu YB, Dulchavsky DS, Kwon D, Arbab AS, et al. Bone marrow-derived mesenchymal stromal cells accelerate wound healing in the rat. Wound Repair Regen. 2006; 14: 471-8.

15. Singh B, Pal L. Sterculia crosslinked PVA and PVA-poly(AAm) hydrogel wound dressings for slow drug delivery: mechanical, mucoadhesive, biocompatible and permeability properties. Journal of the mechanical behavior of biomedical materials. 2012; 9: 9-21.

16. Tarte K, Gaillard J, Lataillade J-J, Fouillard L, Becker M, Mossafa H, et al. Clinical-grade production of human mesenchymal stromal cells: occurrence of aneuploidy without transformation. Blood. 2010; 115: 1549-53.

17. Badiavas EV, Falanga V. Treatment of chronic wounds with bone marrow-derived cells. Arch Dermatol. 2003; 139: 510-6.

18. Rustad KC, Wong VW, Sorkin M, Glotzbach JP, Major MR, Rajadas J, et al. Enhancement of mesenchymal stem cell angiogenic capacity and stemness by a biomimetic hydrogel scaffold. Biomaterials. 2012; 33: 80-90.

19. Falanga V, Iwamoto S, Chartier M, Yufit T, Butmarc J, Kouttab N, et al. Autologous bone marrow-derived cultured mesenchymal stem cells delivered in a fibrin spray accelerate healing in murine and human cutaneous wounds. Tissue Eng. 2007; 13: 1299-312.

20. Lutolf MP, Hubbell JA. Synthetic biomaterials as instructive extracellular microenvironments for morphogenesis in tissue engineering. Nature biotechnology. 2005; 23: 47-55. doi:10.1038/nbt1055.

21. Purna SK, Babu M. Collagen based dressings--a review. Burns. 2000; 26: 54-62.

22. Soland MA, Bego MG, Colletti E, Porada CD, Zanjani ED, St Jeor S, et al. Modulation of human mesenchymal stem cell immunogenicity through forced expression of human cytomegalovirus us proteins. PLoS One. 2012; 7: e36163. doi:10.1371/journal.pone.0036163.

23. Gartner A, Pereira T, Armada-da-Silva PA, Amorim I, Gomes R, Ribeiro J, et al. Use of poly(DL-lactide-epsilon-caprolactone) membranes and mesenchymal stem cells from the Wharton's jelly of the umbilical cord for promoting nerve regeneration in axonotmesis: in vitro and in vivo analysis. Differentiation; research in biological diversity. 2012; 84: 355-65. doi:10.1016/j.diff.2012.10.001.

24. Amado S, Simoes MJ, Armada da Silva PA, Luis AL, Shirosaki Y, Lopes MA, et al. Use of hybrid chitosan membranes and N1E-115 cells for promoting nerve regeneration in an axonotmesis rat model. Biomaterials. 2008; 29: 4409-19. doi:10.1016/j.biomaterials.2008.07.043.

25. Le Blanc K, Ringden O. Immunobiology of human mesenchymal stem cells and future use in hematopoietic stem cell transplantation. Biology of blood and marrow transplantation : journal of the American Society for Blood and Marrow Transplantation. 2005; 11: 321-34. doi:10.1016/j.bbmt.2005.01.005.

26. Leri A, Kajstura J, Anversa P, Frishman WH. Myocardial regeneration and stem cell repair. Current problems in cardiology. 2008; 33: 91-153. doi:10.1016/j.cpcardiol.2007.11.002.

27. Sanchez-Ramos JR. Neural cells derived from adult bone marrow and umbilical cord blood. J Neurosci Res. 2002; 69: 880-93. doi:10.1002/jnr.10337.

28. Wang L, Ott L, Seshareddy K, Weiss ML, Detamore MS. Musculoskeletal tissue engineering with human umbilical cord mesenchymal stromal cells. Regenerative medicine. 2011; 6: 95-109. doi:10.2217/rme.10.98.

29. Phinney DG, Prockop DJ. Concise review: mesenchymal stem/multipotent stromal cells: the state of transdifferentiation and modes of tissue repair--current views. Stem Cells. 2007; 25: 2896-902. doi:10.1634/stemcells.2007-0637.

30. Chen J, Liu R, Yang Y, Li J, Zhang X, Wang Z, et al. The simulated microgravity enhances the differentiation of mesenchymal stem cells into neurons. Neurosci Lett. 2011; 505: 171-5. doi:10.1016/j.neulet.2011.10.014.

31. Du Y, Roh DS, Funderburgh ML, Mann MM, Marra KG, Rubin JP, et al. Adipose-derived stem cells differentiate to keratocytes in vitro. Molecular vision. 2010; 16: 2680-9.

32. Jin G, Prabhakaran MP, Ramakrishna S. Stem cell differentiation to epidermal lineages on electrospun nanofibrous substrates for skin tissue engineering. Acta Biomater. 2011; 7: 3113-22. doi:10.1016/j.actbio.2011.04.017.

33. Al Battah F, De Kock J, Vanhaecke T, Rogiers V. Current status of human adipose-derived stem cells: differentiation into hepatocyte-like cells. ScientificWorldJournal. 2011; 11: 1568-81. doi:10.1100/tsw.2011.146.

34. Bhandari DR, Seo KW, Sun B, Seo MS, Kim HS, Seo YJ, et al. The simplest method for in vitro beta-cell production from human adult stem cells. Differentiation; research in biological diversity. 2011; 82: 144-52. doi:10.1016/j.diff.2011.06.003.

35. Ankrum J, Karp JM. Mesenchymal stem cell therapy: Two steps forward, one step back. Trends in molecular medicine. 2010; 16: 203-9. doi:10.1016/j.molmed.2010.02.005.

36. Nauta AJ, Fibbe WE. Immunomodulatory properties of mesenchymal stromal cells. Blood. 2007; 110: 3499-506 doi:10.1182/blood-2007-02-069716.

37. Togel F, Weiss K, Yang Y, Hu Z, Zhang P, Westenfelder C. Vasculotropic, paracrine actions of infused mesenchymal stem cells are important to the recovery from acute kidney injury. Am J Physiol Renal Physiol. 2007; 292: 9.

38. Zhang M, Mal N, Kiedrowski M, Chacko M, Askari AT, Popovic ZB, et al. SDF-1 expression by mesenchymal stem cells results in trophic support of cardiac myocytes after myocardial infarction. FASEB journal : official publication of the Federation of American Societies for Experimental Biology. 2007; 21: 3197-207. doi:10.1096/fj.06-6558com.

39. Rao MS. Are there morally acceptable alternatives to blastocyst derived ESC? J Cell Biochem. 2006; 98: 1054-61. doi:10.1002/jcb.20723.

40. Vilalta M, Degano IR, Bago J, Gould D, Santos M, Garcia-Arranz M, et al. Biodistribution, long-term survival, and safety of human adipose tissue-derived mesenchymal stem cells transplanted in nude mice by high sensitivity non-invasive bioluminescence imaging. Stem Cells Dev. 2008; 17: 993-1003. doi:10.1089/scd.2007.0201.

41. Fong CY, Chak LL, Biswas A, Tan JH, Gauthaman K, Chan WK, et al. Human Wharton's jelly stem cells have unique transcriptome profiles compared to human embryonic stem cells and other mesenchymal stem cells. Stem Cell Rev. 2011; 7: 1-16.

42. Lozinsky V, Damshkaln L, Kurochkin I, Kurochkin I. Study of cryostructuring of polymer systems: 28. Physicochemical properties and morphology of poly (vinyl alcohol) cryogels formed by multiple freezing-thawing. Colloid journal. 2008; 70: 189-98.

43. Diegelmann RF, Evans MC. Wound healing: an overview of acute, fibrotic and delayed healing. Front Biosci. 2004; 9: 283-9.

44. Jackson WM, Nesti LJ, Tuan RS. Mesenchymal stem cell therapy for attenuation of scar formation during wound healing. Stem cell research \& therapy. 2012; 3: 20. doi:10.1186/scrt111.

45. Ren G, Zhang L, Zhao X, Xu G, Zhang Y, Roberts AI, et al. Mesenchymal stem cell-mediated immunosuppression occurs via concerted action of chemokines and nitric oxide. Cell stem cell. 2008; 2: 141-50. doi:10.1016/j.stem.2007.11.014.

46. Corcione A, Benvenuto F, Ferretti E, Giunti D, Cappiello V, Cazzanti F, et al. Human mesenchymal stem cells modulate B-cell functions. Blood. 2006; 107: 367-72. doi:10.1182/blood-2005-07-2657.

47. Sotiropoulou PA, Perez SA, Gritzapis AD, Baxevanis CN, Papamichail M. Interactions between human mesenchymal stem cells and natural killer cells. Stem cells (Dayton, Ohio). 2006; 24: 74-85. doi:10.1634/stemcells.2004-0359.

48. Nasef A, Chapel A, Mazurier C, Bouchet S, Lopez M, Mathieu N, et al. Identification of IL-10 and TGF-beta transcripts involved in the inhibition of T-lymphocyte proliferation during cell contact with human mesenchymal stem cells. GENE EXPRESSION-CHICAGO THEN ELMSFORD NY--. 2007; 13: 217.

49. Redd MJ, Cooper L, Wood W, Stramer B, Martin P. Wound healing and inflammation: embryos reveal the way to perfect repair. Philosophical transactions of the Royal Society of London Series B, Biological sciences. 2004; 359: 777-84. doi:10.1098/rstb.2004.1466.

50. Chen $\mathrm{L}$, Tredget EE, Wu PY, Wu Y. Paracrine factors of mesenchymal stem cells recruit macrophages and endothelial lineage cells and enhance wound healing. PloS one. 2008; 3: e1886. doi:10.1371/journal.pone.0001886. 